\title{
Biosorption Studies of $\mathrm{Cd}^{2+}$ and $\mathrm{Cr}^{6+}$ from Aqueous Solution Using Cola-Nut Leaves as Low-Cost Biosorbent
}

\author{
Z. H. Ibrahim (D) and M. D. Faruruwa \\ Department of Chemistry, Nigerian Defence Academy, P.M.B. 2109, Kaduna, Nigeria \\ Correspondence should be addressed to Z. H. Ibrahim; zainabibrahimzi10@gmail.com
}

Received 17 October 2019; Revised 2 February 2020; Accepted 29 February 2020; Published 21 April 2020

Academic Editor: José Morillo

Copyright (c) 2020 Z. H. Ibrahim and M. D. Faruruwa. This is an open access article distributed under the Creative Commons Attribution License, which permits unrestricted use, distribution, and reproduction in any medium, provided the original work is properly cited.

\begin{abstract}
Cola-nut leaf is an agricultural waste which was used in this research as biosorbent for the adsorption of $\mathrm{Cd}^{2+}$ and $\mathrm{Cr}^{6+}$ from aqueous solutions. The leaves of cola nut were modified using $0.1 \mathrm{M} \mathrm{HCl}$. Modified cola nut leaves biosorbent showed slightly higher percentage sorption than the unmodified leaves, for both heavy metals with increasing contact time, having greater affinity for $\mathrm{Cd}^{2+}$. The equilibrium sorption data was attained using the batch technique with increased $\mathrm{pH}(9)$ and increased adsorbent dose $\left(1 \mathrm{~g} / 25 \mathrm{~cm}^{3}\right.$ of adsorbate) and initial metal concentration. The functional group of cola nut leaves before and after adsorption was determined using Fourier Transform Infrared Spectroscopy (FTIR). Kinetics data were best fitted to a pseudo-second-order model. Equilibrium data were better described by the Temkin isotherm model with a multilayer adsorption capacity. The study showed that leaves of cola nut are a promising biosorbent for $\mathrm{Cd}^{2+}$ and $\mathrm{Cr}^{6+}$ which could be utilized for industrial wastewater remediation.
\end{abstract}

\section{Introduction}

Heavy metals are naturally occurring contaminants found in the environment as a result of their non-bio-degradability. The toxicity of heavy metals in air, soil, and water is a global issue because it posses threat to human, animal, and plant life. Anthropogenic activity has led to increase in the amount of heavy metals in the environment. Such activities include electroplating and metal treatment processes, printed circuit board (PCB) manufacturing, wood treatment processes, inorganic dye manufacturing, and petroleum refining [1]. Also, research has indicated that cleaning of process tanks and treatment of wastewater may produce reasonable amount of wet sludge having high levels of toxic metals [2].

The following are processes that were used in the removal of heavy metals from the aqueous solution: conventional chemical processes, which include processes such as chemical precipitation, flotation, ion exchange, electrochemical deposition, electro dialysis, electrolytic extraction, reverse osmosis, and cementation [3]. These methods are expensive and cannot remove metals at low concentration
[4]. Owing to low cost and availability of biomass, biosorption has received considerable attention in recent years.

Various plant leaves have been used as adsorbents for the removal of heavy metal ions from a solution [5, 6] and [7]. The search for readily available and more efficient biosorbents for removal of heavy metals from aqueous solution has led to the identification of cola nut leaves, which are evergreen plants, for this purpose.

Treatment of biomass for adsorption helps to desorb inorganic and organic materials adsorbed during plant growth which may affect the adsorption process [8] and also increases the capacity of the sorbent by cleaning up the surface and opening up pores [9]. The best chemical to treat the biomass involves the use of alkalis and inorganic or organic acids [8].

Although there are a number of reviews on the adsorption capacity of various biomasses which deal with elimination of heavy metals, however, considering the complexity of various factors that influence the process, highly-efficient biosorbents that are cost-effective need to be identified. According to Alekseeva et al. [10] in a review, the 
biosorbents with greatest performance for removal of metal ions in the literature is sorption using leaves of neem tree which is an evergreen plant. Hence, the leaves of other evergreen crops (which are available all throughout the year) will be tested for their adsorption capacity. Hence, in this research, biosorption characteristics ( $\mathrm{pH}$, biomass dosage, initial metal concentration, and contact time) were studied for the adsorption of $\mathrm{Cd}^{2+}$ and $\mathrm{Cr}^{6+}$ onto dried cola nut leaves and acid-modified cola nut leaves.

\section{Materials and Methods}

\subsection{Materials}

2.1.1. Equipment. Buck Scientific Atomic Adsorption Spectrophotometer (AAS)-AAS-HP Serial Number: MY14470001, Agilent Technologies FTIR Spectrometer Happ-Ganzel Resolution 8, Stuart Scientific orbital shakerSO1, JENWAY Digital pH meter, digital electronic balance, hot air oven (MINO/53/CLAD), Miller, rotary evaporator, Erlenmeyer flasks and volumetric flasks, Whatman filter paper, sieve, deionized water, beakers, measuring cylinder, stoppers, and masking tape.

2.2. Chemicals and Reagents. All reagents used are of analytical grade.

Cadmium (II) nitrate tetra-hydrate (percentage purity 99\%, MW $308.47 \mathrm{~g} / \mathrm{mol}$ ), potassium dichromate hexa-hydrate (percentage purity 99\%, MW $294.2 \mathrm{~g} / \mathrm{mol}$ ), $\mathrm{NaOH}$ (percentage purity 99\%, MW $40 \mathrm{~g} / \mathrm{mol}$ ), and $\mathrm{HCl}$ (percentage purity $36.5 \%$, specific gravity 1.18125 ).

2.3. Sampling. A composite sample of cola nut leaves was collected made up of leaves obtained from many trees from plantation in Ondo west local government, Ondo state. The leaves were stored in air-tight sacs. It was transported immediately and taken for identification, where a voucher number of 9171 was given to the plant.

2.4. Preparation of Leaves for FTIR Analysis. The dried powdered leaves of cola nut were weighed $(10 \mathrm{~g})$ and mixed with $150 \mathrm{ml}$ of ethanol and kept for 3 days as described by Kumar and Ramaswamy [11]. The extract was filtered using Whatman no. 1 filter paper, and the filtrate was collected. It was evaporated using a rotary evaporator, and the crude was taken for Fourier Transform Infrared Spectrophotometry (FTIR) analysis. It is a tool that can be used to identify the types of chemical bonds in a compound and also the functional groups present in the compound.

2.4.1. Preparation of Cola Nut Leaves. Sample (cola nut leaves) was pretreated according to the method described by Tichaona and Olindah [8]; the plant leaves were washed with tap water and rinsed with distilled water to remove dirt and extraneous materials. It was sun-dried, then pulverized to a fine powder using a miller, sieved to obtain uniform particle size, and oven-dried at $105^{\circ} \mathrm{C} \pm 0.1$ to constant mass. Finally, it was stored in a plastic container. The functional groups in cola nut leaves were determined using the Agilent Technologies FTIR Spectrometer, Serial Number: MY14470001 model 8 .

2.4.2. Modification of the Sample. The acid modification was carried out as described by Ege and Doner [12]. Exactly $10 \mathrm{~g}$ of the powdered sample was mixed with $200 \mathrm{~cm}^{3}$ of $0.1 \mathrm{M}$ $\mathrm{HCl}$ solutions for 72 hours at room temperature and then rinsed with distilled water until a $\mathrm{pH}$ of 7 was obtained. It was dried in an oven for three days at $60^{\circ} \mathrm{C}$ and kept in plastic containers, (labeled ATK) for adsorption processes. A control, untreated cola (UTK), was also used as biosorbent for the adsorption of $\mathrm{Cd}$ and $\mathrm{Cr}$ ions.

2.4.3. Preparation of the Adsorbate. Stock solutions of $\mathrm{Cd}^{2+}$ and $\mathrm{Cr}^{6+}$ metal ions were prepared using the standard method, from which working concentrations (5, 50, 100, 150, and 200) $\mathrm{mg} / \mathrm{L}$ were prepared by serial dilution.

2.5. Batch Biosorption Procedure. For acid-modified cola nut leaves (ATK) and unmodified (UTK) samples, batch experiments were carried out. The powdered sample $(0.1 \mathrm{~g})$ was mixed separately with $25 \mathrm{~cm}^{3}$ metal ion solution of initial concentration $100 \mathrm{mg} / \mathrm{L}$. The mixture was shaken constantly on a shaker at 200 revolutions per minute (rpm) at given time intervals, at the end of which the mixture was filtered using a filter paper, and the filtrate was taken for analysis, as described by Tijani et al. [13]. Residual concentration was immediately determined using an atomic absorption spectrophotometer AAS. This was carried out in triplicate, and the mean value was taken. The removal efficiency (\% sorption) and adsorption capacity were calculated using equations (1) and (2), respectively, as described by Dada et al. [14]:

$$
\begin{gathered}
\% \text { sorption }=\left(\frac{C_{o}-C_{e}}{C_{o}}\right) \times 100, \\
Q_{e}=\frac{C_{o}-C_{e}}{m} V
\end{gathered}
$$

where $C_{o}$ is the initial metal ion concentration in $\mathrm{mg} / \mathrm{L}, C_{e}$ is the equilibrium metal ion concentration in $\mathrm{mg} / \mathrm{L}, m$ is the amount of adsorbent in $\mathrm{g}$, and $V$ is the amount of adsorbate in $\mathrm{cm}^{3}$.

Effect of operational parameters on the adsorption process where thereafter studied.

Effect of adsorbent dose was studied by varying the amount of adsorbent (0.1, 0.2, 0.4, 0.6, 0.8, and $1 \mathrm{~g})$.

Effect of $\mathrm{pH}$ was studied at by varying the $\mathrm{pH}$ of the metal ion solution from 3 to 9 using $0.1 \mathrm{M} \mathrm{NaOH}$ and $0.1 \mathrm{M}$ $\mathrm{HCl}$ for adjustment of $\mathrm{pH}$ as appropriate at optimum dose.

Effect of metal concentration was studied by varying the metal ion concentration $(5,50,100,150$, and $200 \mathrm{mg} / \mathrm{L})$.

Effect of contact time on the uptake of $\mathrm{Cd}^{2+}$ and $\mathrm{Cr}^{6+}$ by ATK and UTK was investigated by varying the time of 
adsorption from $30,60,120,150$, and 180 minutes at optimum experimental conditions.

Equilibrium data obtained was analyzed using isotherm models (Langmuir, Freundlich, and Temkin).

2.5.1. Kinetic Experiment. Batch kinetics was carried out on the removal of the two metal ions from aqueous solutions. The aqueous sample was taken at different time intervals (30, $60,120,150$, and 180 minutes), and the residual concentration of metal ions was determined using AAS. The amount adsorbed at time $t, q_{t}\left(\mathrm{mgg}^{-1}\right)$ was calculated using the following equation [14]:

$$
q_{t}=\frac{C_{o}-C_{t}}{m} V .
$$

\section{Results and Discussion}

3.1. Characterization of Cola Nut Leaves. The prominent vibration band shown in the FTIR Spectrum of cola nut leaves is presented in Table 1. The functional groups and their corresponding wave length are given in the table. These functional groups also participated in the adsorptive studies supporting a physisorption mechanism [15].

The FTIR results for the leaves before and after adsorption show slight change in the wavelength $\left(\Delta \mathrm{cm}^{-1}\right)$, but does not result in the formation of a new functional group. This slight change could be as a result of electronic interaction. In such cases, the type of bonding that has taken place is a physical bonding, where no new bond is formed. The FTIR analysis shows that the reaction taking place is a physisorption reaction. Some of the characteristics of the physisorption reaction include particles are strongly mobile on the surface of the adsorbent because they are relatively far from the surface plane due to the low binding energy and such reaction requires low desorption temperature [17]. A similar result was obtained by Ajaelu and Dawodu. [15], for the biosorptive removal of nickel (II) by Mangifera indica seed.

\subsection{Effects of Operational Parameters on the Removal of $\mathrm{Cd}^{2+}$.} Effect of adsorbent dose is carried out in order to maximize the interaction between the adsorbent and metal ions. The effect of biosorbent dose on $\mathrm{Cr}$ (VI) ion adsorption onto ATK and UTK is presented in Figure 1. The percentage removal increased from $99.86-99.99 \%$ for ATK and 95.89-99.39\% for UTK as biosorbent dose increases from $0.1-1 \mathrm{~g}$. Figure 2 shows the plot of percentage removal of $\mathrm{Cd}^{2+}$ metal ions against varying amounts of ATK and UTK. The result indicated that the percentage removal of Cd (II) ions increases with increasing adsorbent doses as also observed by Ogunsile and Babarinde [18] with a removal efficiency of 99.30 to $99.80 \%$ for ATK and 99.00 to $99.50 \%$ for UTK, thereafter maintaining equilibrium. The removal efficiency of the metal ions depends on quantity of the biosorbent. The increase in percentage removal of Cd (II) and $\mathrm{Cr}$ (VI) ions with increase in adsorbent dose was due to the availability of more adsorbent surfaces for the solutes to be adsorbed.

The effect of $\mathrm{pH}$ on $\mathrm{Cr}$ (VI) and Cd (II) ion adsorption is presented in Figures 3 and 4, respectively. $\mathrm{pH}$ is an important parameter influencing heavy metal adsorption from aqueous solutions. It affects both the surface charge of the adsorbent and the degree of ionization of the heavy metal in the solution [19]. At low $\mathrm{pH}$, the surface of the biomass would be protonated and would therefore repel $\mathrm{Cr}$ and $\mathrm{Cd}$ ions [20]; hence, the sorption of metal ion is minimal. Increasing the $\mathrm{pH}$ resulted in increase in the number of negatively charged sites that favored the electrostatic attraction [21] of the $\mathrm{Cr}$ (VI) and Cd (II) ions. Leyva et al. [22] reported a similar result for the adsorption Co (II) ions onto activated carbon. Complexation and precipitation of metal could take place in the solution, if contact between adsorbent and adsorbate is low [23]. Hence, the formation of complexes was minimized by increased amount of adsorbent $(1 \mathrm{~g})$ used and increased concentration of adsorbate. Furthermore, according to Gonçalves et al. [24], the tendency of ion capture by adsorbent as a result of $\mathrm{pH}$ could be explained by association and dissociation of some functional groups, e.g., carboxyls, where most carboxyl groups are undissociated in low $\mathrm{pH}$ levels, but can participate in complex reactions, while increased $\mathrm{pH}$ rate results in functional groups (carboxyls) having negative charges and therefore may attract positive charged ions. The maximum removal efficiency for the adsorption of Cd ions was $96.85 \%$ and $96.36 \%$ for both ATK and UTK adsorbents, respectively, at an optimum $\mathrm{pH}$ of 9.0.

Consequently, the working $\mathrm{pH}$ value for $\mathrm{Cr}$ (VI) ions removal onto ATK and UTK was chosen as 8.0, which was also obtained by Antunes et al. [25] in their research.

The effect of varying concentration of $\mathrm{Cr}$ (VI) and Cd (II) ion on adsorption onto ATK and UTK is shown in Figures 5 and 6, respectively. The percentage removal increased as the initial concentration of metal ions increased until equilibrium was reached. According to Dang et al. [26], this result is expected, as the concentration serves as a motivating force to surmount mass transfer resistances linking the aqueous and solid phases. It can also be depicted that, increase in the initial metal ion concentration resulted in increase in number of collisions among the metal ion and the biosorbent. The initial $\mathrm{Cr}$ (VI) and Cd (II) ions concentration was varied from $5.00-200.00 \mathrm{mg} / \mathrm{L}$ under optimum conditions, and the optimum value of $\mathrm{Cr}$ (VI) ion adsorption was observed at $99.99 \%$ for ATK and $99.99 \%$ for UTK, as shown in Figure 5. Also, for Cd (II), as the concentration increased, the amount of Cd (II) ions adsorbed also increased up to $50 \mathrm{mg} / \mathrm{L}$, after which no net adsorption occurred. It can be depicted that increasing the initial concentration increased the sorption gradient, and hence percentage removal increased. After the initial concentration of $50.00 \mathrm{mg} / \mathrm{L}$, biomass saturation occurred, and the biomass attained equilibrium.

The increase in the quantity of metal ion uptake can also be as a consequence of increased collision between metal ions and the surface of the biosorbent and increased rate of metal ions diffusion onto the biosorbent surface [27] due to 
TABLE 1: FTIR analysis of cola nut leaves before and after adsorption with their corresponding functional groups [16].

\begin{tabular}{lcccc}
\hline S/N & $\begin{array}{c}\text { Vibration peaks of cola nut leaves } \\
\text { before adsorption }\left(\mathrm{cm}^{-1}\right)\end{array}$ & Functional groups & $\begin{array}{c}\text { Vibration peaks of cola nut leaves } \\
\text { after adsorption }\left(\mathrm{cm}^{-1}\right)\end{array}$ & $\begin{array}{c}\text { Change in wavelength } \\
\left(\Delta \mathrm{cm}^{-1}\right)\end{array}$ \\
\hline 1 & 3384.4 & O-H & 3276.3 & 108.1 \\
2 & 2922.2 & $\mathrm{C}-\mathrm{H}_{2}$ stretching & 2918.5 & 3.7 \\
3 & 2855.1 & $\mathrm{CH}_{3}$ & 28561.4 & 3.7 \\
4 & 1733.2 & $\mathrm{C}-\mathrm{O}-\mathrm{O}-\mathrm{CO}-$ saturated & 1729.5 & 3.7 \\
5 & 1449.2 & acid anhydride & 1438.8 & 7.4 \\
6 & 1375.4 & $\mathrm{~N}-\mathrm{N}=\mathrm{O}$ & 1315.8 & 59.6 \\
7 & 1162.9 & $\mathrm{CH}$ symmetrical & 1148.0 & 14.9 \\
8 & 1066.0 & deformation & 1032.5 & 33.5 \\
\hline
\end{tabular}

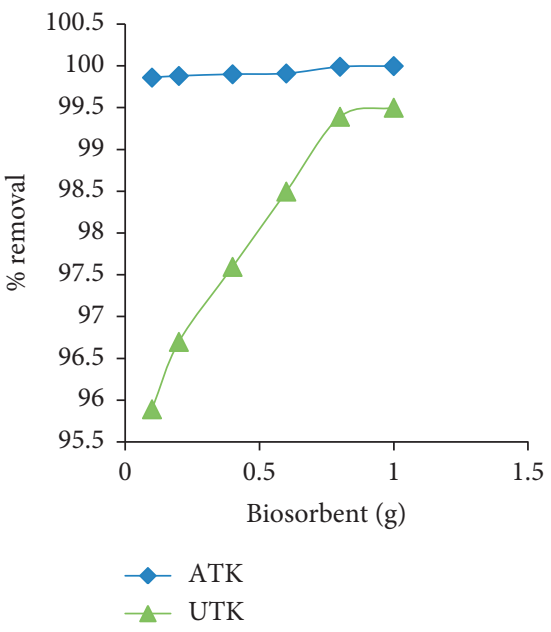

Figure 1: \% removal of $\mathrm{Cr}(\mathrm{VI})$ ions versus biosorbent dose.

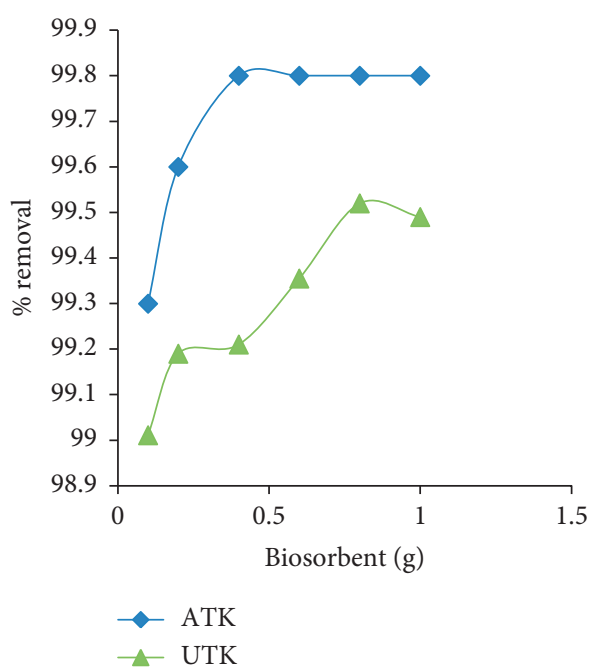

Figure 2: \% removal of Cd (II) ions versus biosorbent dose.

availability and accessibility of vacant site for metal ion adsorption. Hence, equilibrium is established, as the active sites of both biosorbents attained saturation point and no additional adsorption [28].

The effect of contact time on Cr (VI) and Cd (II) ion adsorption onto ATK and UTK is presented in Figures 7 and

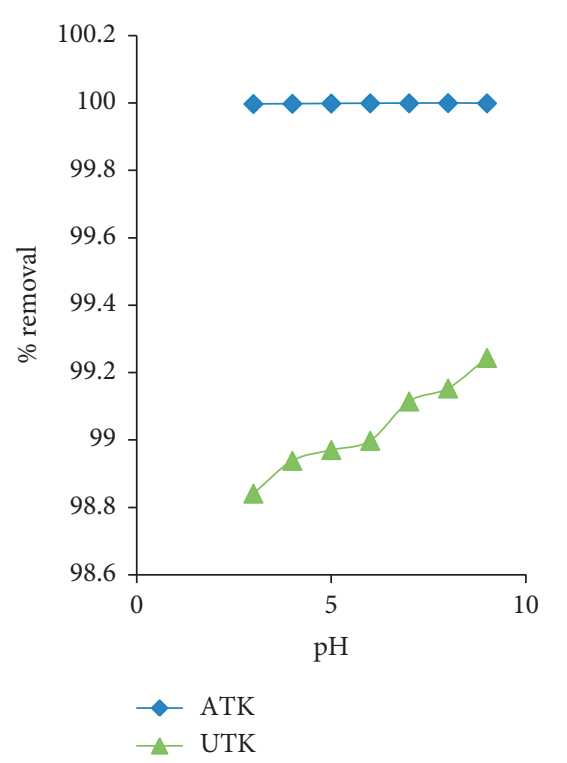

Figure 3: \% removal of $\mathrm{Cr}(\mathrm{VI})$ ions versus $\mathrm{pH}$.

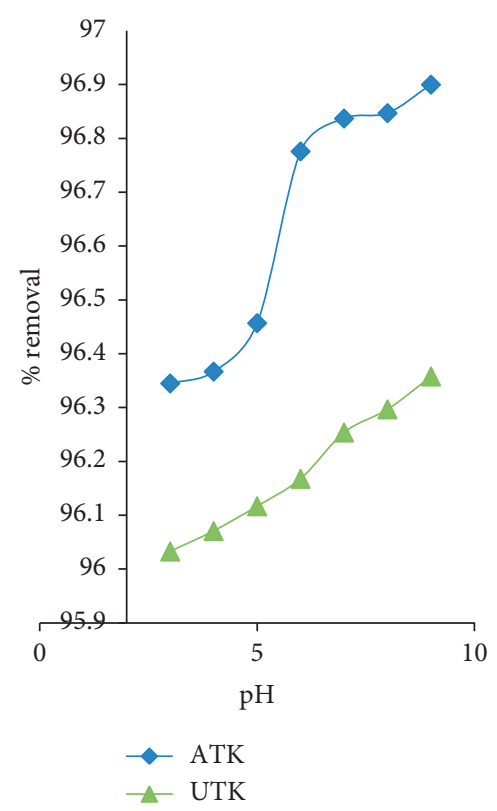

Figure 4: \% removal of Cd (II) ions versus $\mathrm{pH}$. 


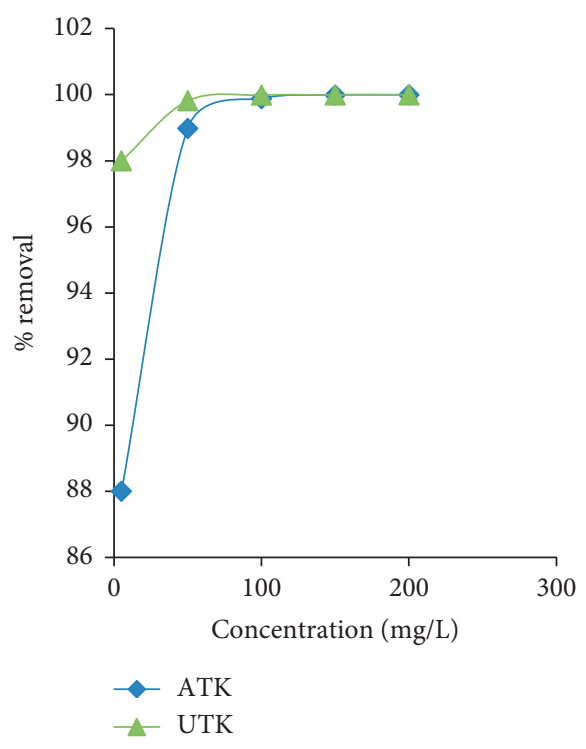

Figure 5: \% removal of $\mathrm{Cr}(\mathrm{VI})$ ions versus concentration.

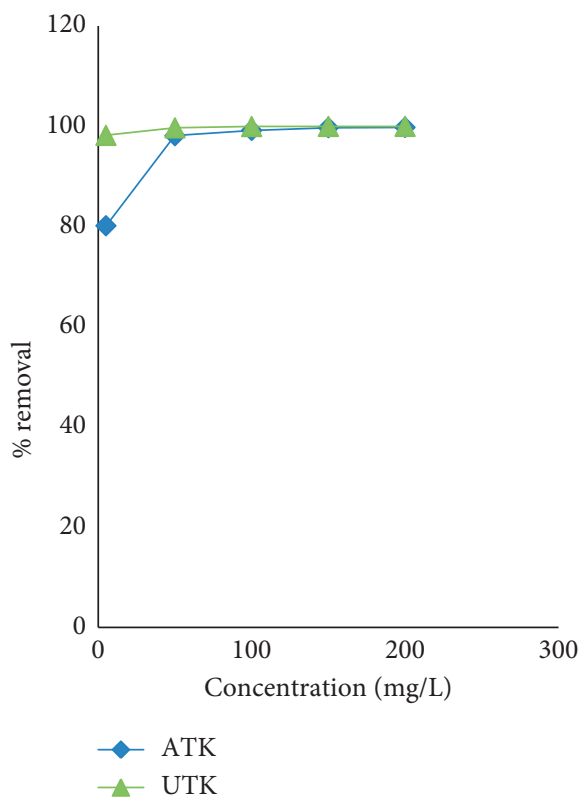

FIGURE 6: \% removal of Cd (II) ions versus concentrate.

8 , respectively. It can be clearly observed that the percentage adsorption generally increased until the time reached 150.00 minutes for ATK and UTK. The removal of Cd (II) ions increased from $99.85-99.99 \%$ for ATK and 99.67-99.93\% for UTK as time increases from $30-180$ minutes. It is clearly observed that the percentage adsorption of $\mathrm{Cr}$ (VI) ion gradually increased until time reached 150.00 minutes for ATK and UTK. After this time, there was slight decrease in the adsorption percentage. Thus, 150 minutes was chosen as the optimum time. The highest percentage of adsorption was found to be $96.83 \%$ for ATK and $96.37 \%$ for UTK. Thereafter, the surface adsorption sites became exhausted, and the removal of metal ion is

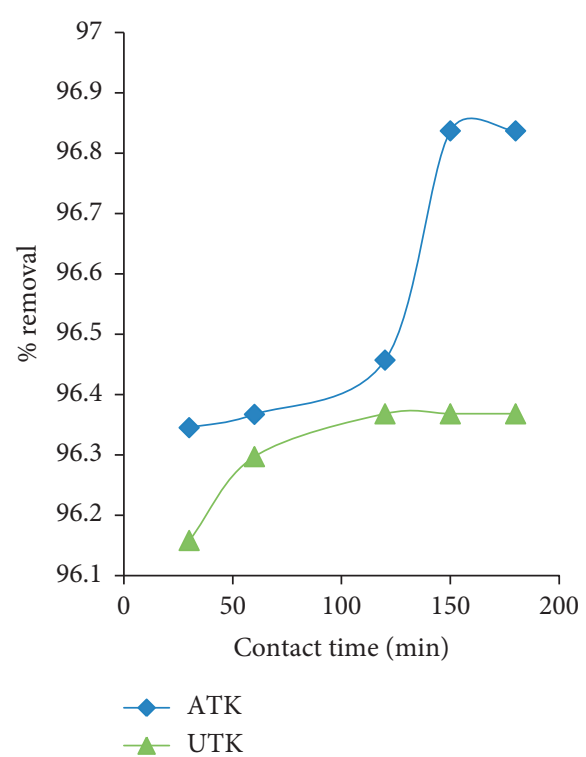

Figure 7: \% removal of $\mathrm{Cr}$ (VI) ions versus contact time (mins).

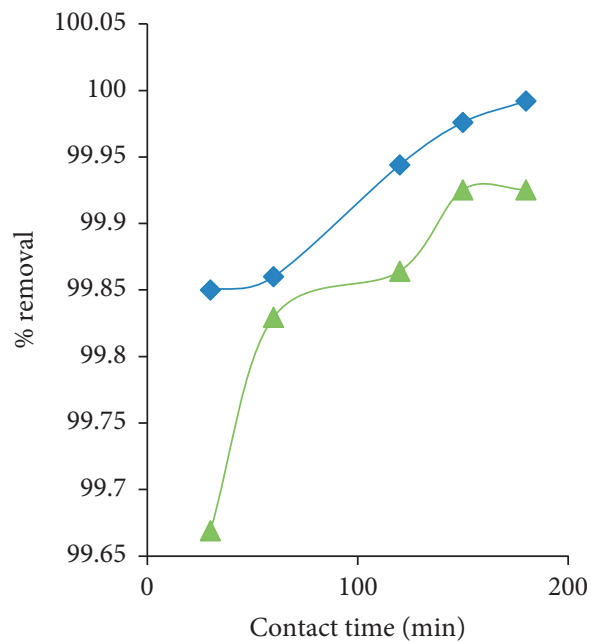

Figure 8: \% removal of Cd (II) ions versus contact time.

controlled by the rate at which the adsorbate is moved from the exterior to the inner sites of the biomass particles [29]. Similar results were reported using wheat shell as the biosorbent.

3.3. Biosorption Kinetics. The adsorption kinetics of $\mathrm{Cd}^{2+}$ and $\mathrm{Cr}^{6+}$ was investigated to establish the rate of mechanism of the adsorption process. Pseudo-first-order and pseudo-second order are the rate equations that were used to analyze the experimental data. The evaluated kinetics parameters obtained from the linear plots of the models (Figures 9(a)-9(h)) are presented in Table 1 for the adsorption of $\mathrm{Cd}^{2+}$ and $\mathrm{Cr}^{6+}$.

3.3.1. Pseudo-First-Order Kinetics. The pseudo-first-order equation (Lagergren's equation) describes adsorption according to the adsorption capacity of solid. The model 


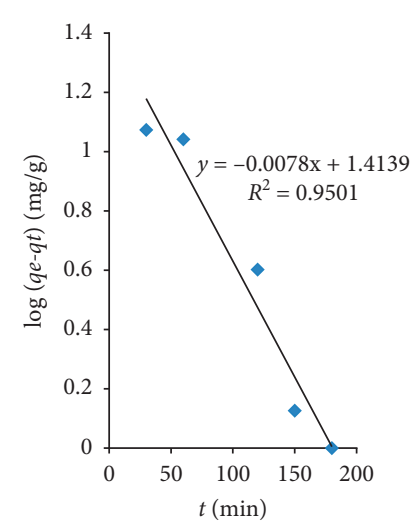

(a)

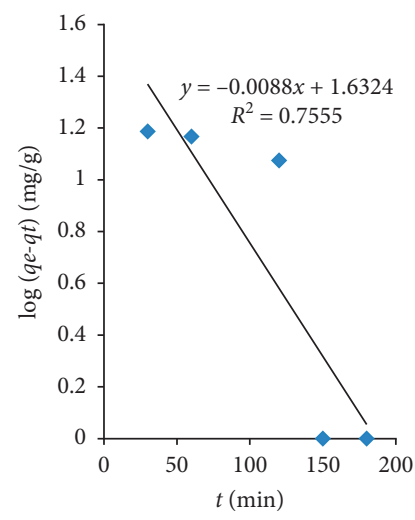

(e)

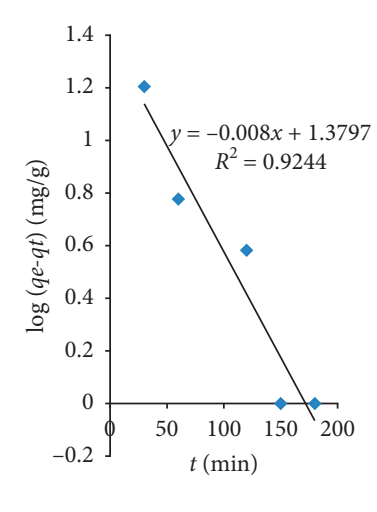

(b)

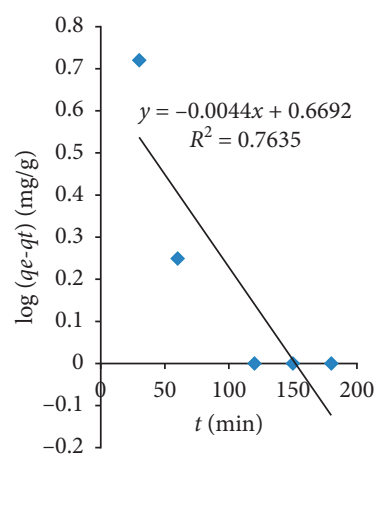

(f)

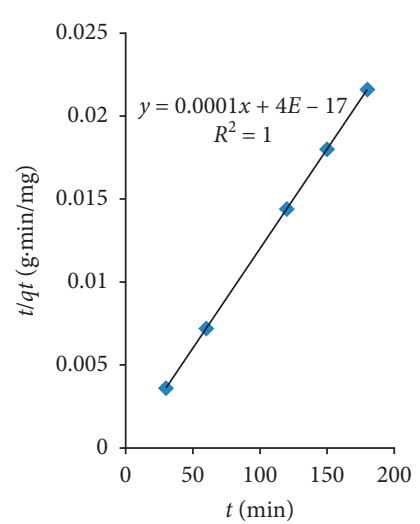

(c)

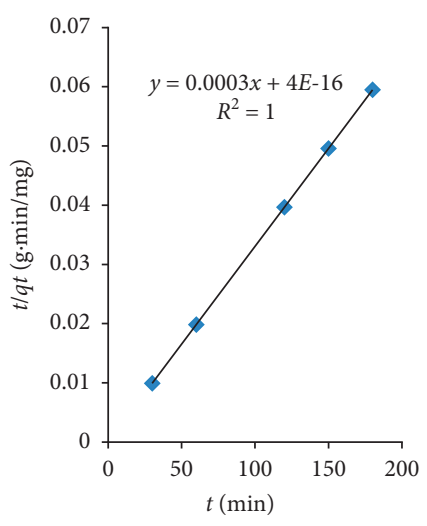

(g)

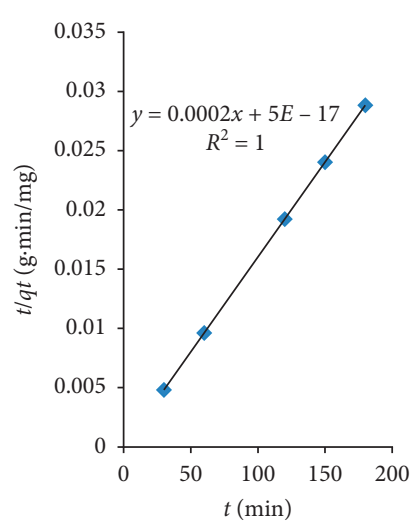

(d)

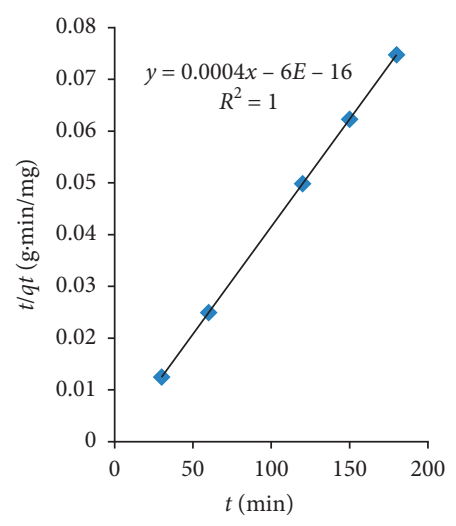

(h)

Figure 9: Linear plots of (a) pseudo-first-order and (b) pseudo-second-order for $\mathrm{Cd}^{2+}$ adsorption by ATK and (c) pseudo-first-order and (d) pseudo-second-order for $\mathrm{Cr}^{6+}$ adsorption by ATK. Linear plots of (e) pseudo-first-order and (f) pseudo-second-order for Cd ${ }^{2+}$ adsorption by UTK and (g) pseudo-first-order and (h) pseudo-second-order for $\mathrm{Cr}^{6+}$ adsorption by UTK.

assumes that one metal ion is adsorbed on one site of the adsorbent surface [14].

The linear equation of pseudo-first-order is given as

$$
\log \left(q_{e}-q_{t}\right)=\log q_{e}-\frac{k_{1} t}{2.303}
$$

where $q_{e}$ is the amount of metal ion adsorbed at equilibrium per unit weight of the adsorbent $\left(\mathrm{mg}^{\mathrm{g}} \mathrm{g}^{-1}\right) \cdot q_{t}$ is the amount of metal ion adsorbed at any time $(\mathrm{mg} / \mathrm{g}) . k_{1}$ is the pseudo-firstorder rate constant $\left(\mathrm{min}^{-1}\right)$

The plot of $\log \left(q_{e}-q_{t}\right)$ versus $t$ gives a linear relationship and $k_{1}$ and $q_{e}$ were obtained from the slope and intercept of the plot.

3.3.2. Pseudo-Second-Order Kinetics. The model assumes that one metal ion is adsorbed onto two sorption sites on the adsorbent surface [14]. The pseudo-second-order linear expression is given as

$$
\frac{t}{q_{t}}=\frac{1}{k_{2} q_{e}^{2}}+\frac{1}{q_{e}} t,
$$

where $k_{2}$ is the rate constant of pseudo-second-order adsorption ( $\mathrm{g} / \mathrm{mg} \mathrm{min})$.
Based on the evaluated parameters of the pseudo-firstorder model of Cd (II) ions biosorption onto ATK and UTK biosorbents, $q_{e}$ values indicated that biosorbents adsorbed more Cd (II) ions within a short contact time and the correlation of determination, and $R^{2}$ values indicated that the biosorption of $\mathrm{Cd}$ (II) ion onto the two biosorbent fits pseudo-first-order due to good correlation between log $\left(q_{e}-\right.$ $q_{t}$ ) and $t$. Also, the correlation parameters of the pseudosecond-order model of Cd (II) ion biosorption onto ATK and UTK biosorbents shows $R^{2}$ value that suggests the biosorption of Cd (II) ion onto the two biosorbents fits best into the pseudo-second-order model than pseudo-first-order due to better correlation between $t / q_{t}$ and $t$, as shown in Table 2. Similar results were obtained by Wang et al. [27].

Table 2 also shows the correlation parameters of the pseudo-first-order and pseudo-second-order model of $\mathrm{Cr}$ (VI) ions biosorption onto ATK and UTK biosorbents. The $q_{e}(5.1161 \mathrm{mg} / \mathrm{g}$ for ATK and $1.9527 \mathrm{mg} / \mathrm{g}$ for UTK) values indicated that less amount of $\mathrm{Cr}$ (VI) ions were adsorbed within a limited time, and the correlation of determination of $R^{2}$ (0.7555 for ATK and 0.7635 for UTK) suggested that biosorption of $\mathrm{Cr}$ (VI) ions fit into the pseudo-first-order model. Also, the $q_{e}(4.1120 \mathrm{mg} / \mathrm{g}$ for ATK and $3.9737 \mathrm{mg} / \mathrm{g}$ for UTK) values indicated less amount of Cd (II) ions adsorption with good correlation value $R^{2}(0.9501$ for ATK and 
TABLE 2: Evaluated parameters of pseudo-first-order and pseudo-second-order for Cd (II) and Cr (VI) metal ion biosorption onto ATK and UTK.

\begin{tabular}{|c|c|c|c|c|}
\hline Model & Adsorbent & $q_{e}(\mathrm{mg} / \mathrm{g})$ & $k_{1}\left(\min ^{-1}\right)$ & $R^{2}$ \\
\hline \multirow{4}{*}{ Pseudo-first-order } & ATK for $\mathrm{Cd}^{2+}$ & 4.1120 & 0.018 & 0.9501 \\
\hline & UTK for $\mathrm{Cd}^{2+}$ & 3.9737 & 0.0184 & 0.9244 \\
\hline & ATK for $\mathrm{Cr}^{6+}$ & 5.1161 & 0.0202 & 0.7555 \\
\hline & UTK for $\mathrm{Cr}^{6+}$ & 1.9527 & 0.0101 & 0.7635 \\
\hline \multirow{5}{*}{ Pseudo-second-order } & & $q_{e}(\mathrm{mg} / \mathrm{g})$ & $k_{2}(\mathrm{~g} / \mathrm{mg} \min )$ & $R^{2}$ \\
\hline & ATK for $\mathrm{Cd}^{2+}$ & 1.45 & 2.303 & 1 \\
\hline & $\mathrm{UTK}$ for $\mathrm{Cd}^{2+}$ & 1.453 & 4.609 & 1 \\
\hline & ATK for $\mathrm{Cr}^{6+}$ & 0.034 & 6.909 & 1 \\
\hline & $\mathrm{UTK}$ for $\mathrm{Cr}^{6+}$ & 1.345 & 9.212 & 1 \\
\hline
\end{tabular}

0.9244 for UTK), which suggest that biosorption of Cd (II) ions fits into the pseudo-first-order model. The pseudosecond-order model shows the correlation value, $R^{2}$ (1.00 for ATK and 1.00 for UTK biosorbents) for the adsorption of both $\mathrm{Cr}$ (VI) and Cd (II) ions, which fits into the pseudosecond-order model than the pseudo-first-order model due to better correlation between $t / q_{t}$ and $t$, as also described by Igwe et al. [30].

3.4. Adsorption Isotherm. The adsorption isotherm is an expression which gives a relationship between the quantity of solute adsorbed and the amount of solute residual in a given solution. Langmuir, Freundlich, and Temkin isotherms have being used to analyze the equilibrium adsorption models. The Langmuir isotherm model explains a monolayer coverage of the solute on a uniform surface of an adsorbent and that saturation coverage is the complete use of the binding sites [12], which can contain only one adsorbate. The equation for thelinear Langmuir isotherm is given as

$$
\frac{C_{e}}{q_{e}}=\frac{1}{q_{0}} \cdot C_{e}+\frac{1}{K_{L} q_{0}} .
$$

The Langmuir isotherm constant $K_{L}\left(\mathrm{~L} \cdot \mathrm{mg}^{-1}\right) R_{L}$, which is a dimensionless constant, and other parameters are used to evaluate the Langmuir isotherm from the linear plot of $C_{e} /$ $Q_{e}$ against $C_{e}$.

The Freundlich isotherm model describes both monolayer and multilayer. It assumes heterogeneity and the exponential distribution of active sites and their energies [14]. The linear form of the Freundlich equation is given as

$$
\log q_{e}=\log K_{F}+\log \frac{1}{n} C_{e} .
$$

The Freundlich isotherm constants and $K_{f}$, sorption intensity $(n)$ are parameters characteristic of the Freundlich isotherm used for evaluation, obtained from the linear plot of $\log Q_{e}$ against $\log C_{e}$.

The Temkin isotherm contains a factor that clearly takes into account of adsorbent-adsorbate interactions. The model assumes that heat of adsorption for all molecules in a layer would decrease linearly rather than logarithmic with coverage [31]. The linear equation for plot of $q_{e}$ against in $C_{e}$ is

$$
q_{e}=\frac{R T}{b_{T} \operatorname{In} A}+\frac{R T}{b_{T} \operatorname{In} C_{e}} .
$$

Table 3 shows the correlation parameter of the Langmuir isotherm for Cd (II) ions biosorption onto ATK and UTK biosorbents. $R_{L}$ (0.0046 for ATK and 0.0064 for UTK biosorbents) indicates that the biosorption of Cd (II) ion by biosorbents was favourable and coefficient of determination, $R^{2}$ (0.3707 for ATK and 0.1803 for UTK), signifies that the biosorption does not fit into the Langmuir isotherm.

Table 3 shows the Freundlich isotherm constants and correlation coefficient for Cd (II) ions biosorption onto ATK and UTK biosorbents, $n$ (0.3749 for ATK and 0.3966 for UTK biosorbents) values indicated favourable biosorption (since $1 / n<1)$, and $R^{2}(0.5617$ for ATK and 0.6256 for UTK biosorbents) values indicated that sorption of $\mathrm{Cd}$ (II) ions onto biosorbents fit into the Freundlich isotherm than Langmuir.

Table 3 also shows the correlation parameter of the Langmuir isotherm for $\mathrm{Cr}$ (VI) ions biosorption onto ATK and UTK biosorbents. $R_{L}$ (0.000599 for ATK and 0.0000111 for UTK biosorbents) values indicated that the biosorption of Cr (VI) ion onto UTK biosorbents was favourable, and $R^{2}$ (0.548 for ATK and 0.5258 for UTK biosorbents) values show that the process of $\mathrm{Cr}$ (VI) ion adsorption onto ATK biosorbent fit into the Langmuir isotherm as also described by Wang et al. [27].

Table 3 shows the Freundlich isotherm constants and correlation coefficient for $\mathrm{Cr}$ (VI) ions biosorption onto ATK and UTK biosorbents. $R^{2}$ (0.6477 for ATK and 0.6985 for UTK biosorbents) values indicated that biosorption of $\mathrm{Cr}$ (VI) ions onto UTK biosorbent fit into the Freundlich isotherm.

The Temkin isotherm model describes $b_{T}$ as a constant which is related to the heat of adsorption and $A_{T}$ as the equilibrium binding constant $\left(\mathrm{Lg}^{-1}\right)$. Table 3 shows the low heat of adsorption, which is an indicator of a physisorption type of reaction and the low binding energy. The $R^{2}$ values obtained from the Temkin isotherm indicate better correlation when compared to other isotherms tested. Adsorption of Cd ion by UTK does not fit into the model, while $\mathrm{Cr}$ can best be described by the Temkin isotherm.

Table 4 shows the maximum adsorption capacity of some adsorbents used for the adsorption of $\mathrm{Cd}$ and $\mathrm{Cr}$ ions. It can be seen that cola nut leaves have high amount of $q_{m}$, therefore being a good adsorbent. 
TABLE 3: Evaluated parameters of Langmuir, Freundlich, and Temkin isotherms for Cd (II) and Cr (VI) metal ion biosorption onto ATK and UTK.

\begin{tabular}{|c|c|c|c|c|c|}
\hline Model & Biosorbents & $Q_{o}(\mathrm{mg} / \mathrm{g})$ & $K_{L}(\mathrm{~L} / \mathrm{mg})$ & $R_{L}$ & $R^{2}$ \\
\hline \multirow{4}{*}{ Langmuir } & ATK for $\mathrm{Cd}^{2+}$ & 178.57 & 2.15 & 0.0046 & 0.3707 \\
\hline & UTK for $\mathrm{Cd}^{2+}$ & 555.56 & 1.56 & 0.0064 & 0.1803 \\
\hline & ATK for $\mathrm{Cr}^{6+}$ & 200 & 16.67 & 0.000599 & 0.548 \\
\hline & UTK for $\mathrm{Cr}^{6+}$ & 185.19 & 899.97 & 0.000011 & 0.5258 \\
\hline \multirow{5}{*}{ Freundlich } & & $K_{f}$ & & $R^{2}$ \\
\hline & ATK for $\mathrm{Cd}^{2+}$ & 17.972 & \multicolumn{2}{|c|}{0.3749} & 0.5617 \\
\hline & UTK for $\mathrm{Cd}^{2+}$ & 218.85 & \multicolumn{2}{|c|}{0.3966} & 0.6256 \\
\hline & ATK for $\mathrm{Cr}^{6+}$ & 13.129 & \multicolumn{2}{|c|}{1.5035} & 0.6477 \\
\hline & UTK for $\mathrm{Cr}^{6+}$ & 5.0298 & \multicolumn{2}{|c|}{1.058} & 0.6985 \\
\hline \multirow{5}{*}{ Temkin } & & $b_{T}$ & $A_{T}\left(\mathrm{Lg}^{-1}\right)$ & $B$ & $R^{2}$ \\
\hline & ATK for $\mathrm{Cd}^{2+}$ & 0.00123 & 1.219 & 6784.7 & 0.855 \\
\hline & UTK for $\mathrm{Cd}^{2+}$ & 0.0025 & 295.35 & 404.91 & 0.1299 \\
\hline & ATK for $\mathrm{Cr}^{6+}$ & 0.0065 & 1.10 & 1280 & 0.9553 \\
\hline & UTK for $\mathrm{Cr}^{6+}$ & 0.0064 & 6.380 & 1303.3 & 0.7828 \\
\hline
\end{tabular}

TABLe 4: $q_{m}$ of various adsorbents for the removal of Cd (II) and Cr (VI) ions.

\begin{tabular}{|c|c|c|c|}
\hline $\begin{array}{l}\text { Adsorbent used for the removal of metal ions from } \\
\text { solution }\end{array}$ & $\begin{array}{l}\text { Type of metal ion } \\
\text { adsorbed }\end{array}$ & $\begin{array}{l}\text { Maximum monolayer adsorption capacity } \\
\left(q_{m} \mathrm{mg} / \mathrm{g}\right)\end{array}$ & Reference \\
\hline Activated coal & Cr III & 13.552 & {$[23]$} \\
\hline Oxidized MW carbon nanotubes & Cr VI & 4.262 & {$[32]$} \\
\hline Rhizopus arrhizus for removal & Cr VI & 23.92 & {$[33]$} \\
\hline Dried activated sludge & Cd II & 84.30 & {$[34]$} \\
\hline Tamarindus indica seeds & Cr VI & 0.098 & {$[35]$} \\
\hline Coconut copra meal & Cd II & 4.92 & {$[36]$} \\
\hline Crude tamarind fruit shells (CTFS) & Cr VI & 74.62 & \\
\hline HCl-treated shells (H-TS) & Cr VI & 140.84 & {$[37]$} \\
\hline Oxalic acid-treated shells (O-TS) & Cr VI & 151.51 & \\
\hline Orange peels & Cd II & 123.65 & {$[38]$} \\
\hline Pinus bark & Cd II & 10.384 & {$[24]$} \\
\hline Pinus bark & Cr VI & -10.661 & \\
\hline ATK cola nut leaves & Cr VI & 178.57 & \\
\hline UTK cola nut leaves & $\mathrm{Cr}$ VI & 555.56 & \\
\hline ATK cola nut leaves & Cd II & 200 & \\
\hline UTK cola nut leaves & Cd II & 185.19 & \\
\hline
\end{tabular}

\section{Conclusions}

In this research, the adsorption of Cd II and Cr VI using cola nut leaves biomass was studied. The investigation of the equilibrium sorption was carried out at room temperature. The study revealed that adsorption of Cd (II) ions and Cr (VI) ions onto acid-treated and untreated leaves depended on the operational parameters. It can also be depicted that the untreated cola nut leaves have high adsorption capacity compared to other adsorbents. The pseudo-second order model best described the kinetics of the biosorption of the metal ions. The sorption data fitted into Langmuir, Freundlich, and Temkin isotherm models and were better described by the Temkin model. It can be concluded that leaves of cola nut tree are a potential and active biosorbent for removal of cadmium and chromium ions from its aqueous solution and can thereby serve as a bioremediator in industrial waste water treatment.

\section{Data Availability}

The data used to support the findings of this study are included within the article.

\section{Conflicts of Interest}

The authors declare no conflicts of interest.

\section{Acknowledgments}

The authors wish to acknowledge all staff of the chemistry department of the Nigerian Defence Academy (NDA) for their contribution one way or the other in carrying out the research. The authors wish to thank their families for their endless support. 


\section{References}

[1] L. Sorme and R. Lagerkvist, "Sources of heavy metals in urban wastewater in Stockholm," The Science of the Total Environment, vol. 298, no. 1-3, pp. 131-145, 2002.

[2] O. B. Akpor, G. O. Ohiobor, and T. D. Olaolu, "Heavy metal pollutants in wastewater effluents: sources, effects and remediation," Advances in Bioscience and Bioengineering, vol. 2, no. 4, pp. 37-43, 2014.

[3] T. Mohammadi, A. Moheb, M. Sadrzadeh, and A. Razmi, "Modeling of metal ion removal in waste water by electrodialysis," Separation and Purification Technology, vol. 41, no. 1, pp. 73-82, 2005.

[4] N. R. Bishnoi, M. Bajaj, N. Sharma, and A. Gupta, "Adsorption of $\mathrm{Cr}(\mathrm{VI})$ on activated rice husk carbon and activated alumina," Bioresource Technology, vol. 91, no. 3, pp. 305-307, 2004.

[5] N. A. A. Babarinde, J. O. Babalola, and R. A. Sanni, "Biosorption of lead ions from aqueous solution by maize leaf," International Journal of Physical Sciences, vol. 1, no. 1, pp. 023-026, 2006.

[6] I. Oboh, E. Aluyor, and T. Audu, "Biosorption of heavy metal ions from aqueous solutions using a biomaterial," Leonardo Journal of Sciences, vol. 14, pp. 58-65, 2009.

[7] D. H. K. Reddy, Y. Harinath, K. Seshaiah, and A. V. R. Reddy, "Biosorption of $\mathrm{Pb}$ (II) from aqueous solutions using chemically modified Moringa oleifera tree leaves," Chemical Engineering Journal, vol. 162, pp. 626-634, 2010.

[8] N. Tichaona and H. Olindah, "Equilibrium isotherm analysis of the biosorption of $\mathrm{Zn}^{2+}$ ions by acid treated zea mays leaf powder," International Journal of Advances in Engineering \& Technology, vol. 6, no. 1, pp. 128-139, 2013.

[9] C. Mahamadi and R. Chapeyama, "Divalent metal ion removal from aqueous solution by acid-treated and garlictreated Canna indica roots," Journal of Applied Sciences and Environmental Management, vol. 15, no. 1, pp. 97-103, 2011.

[10] A. A. Alekseeva, D. D. Fazullin, D. A. Kharlyamov et al., "The use of leaves of different tree species as a sorption material for extraction of heavy metal ions from aqueous media," International Journal of Pharmacy \& Technology, vol. 8, no. 2, pp. 1435-14391, 2016.

[11] R. A. Kumar and M. Ramaswamy, "Phytochemical screening by FTIR spectroscopic analysis of leaf extracts of selected Indian Medicinal plants," International Journal of Current Microbiology and Applied Sciences, vol. 3, no. 1, pp. 395-406, 2014.

[12] A. Ege and G. Doner, "A new biosorbent for the removal of $\mathrm{Cu}$ (II) from aqueous solution; red marine alga, Ceramium rubrum," E3S Web of Conferences, vol. 1, p. 25009, 2013.

[13] J. O. Tijani, M. Musah, and I. Blessing, "Sorption of lead (II) and copper (II) ions from aqueous solution by acid modified and unmodified gmelina arborea (verbenaceae) leaves," Journal of Emerging Trends in Engineering and Applied Sciences (JETEAS), vol. 2, no. 5, pp. 734-740, 2011.

[14] A. O. Dada, D. F. Latona, O. J. Ojediran, and O. O. Nath, "Adsorption of $\mathrm{Cu}$ (II) onto bamboo supported manganese (BS-Mn) nanocomposite: effect of operational parameters, kinetic, isotherms, and thermodynamic studies," Journal of Applied Sciences and Environmental Management, vol. 20, no. 2, pp. 409-422, 2016.

[15] C. A. Ajaelu and M. O. Dawodu, "Sequestration of cadmium ions onto mango (Mangifera indica) seed biomass: kinetics and equilibrium studies," Journal of Chemical and Pharmaceutical Research, vol. 5, no. 8, pp. 174-180, 2015.
[16] H. Reddy, D. S. Kumar, Srisudharson, and N. Parthi, "Near infra red spectroscopy-an overview," International Journal of ChemTech Research, vol. 3, no. 2, pp. 825-836, 2011.

[17] K. Christmann, "Thermodynamics and kinetics of adsorption, subtitle: what can we learn about adsorption systems from thermodynamic and kinetic measurements?" in Experimental and Theoretical Methods in Surface Science, Institut für Chemie und Biochemie, Freie Universität Berlin, Berlin, Germany, 2012.

[18] B. O. Ogunsile and O. A. Babarinde, "The biosorption of cadmium and lead ions from aqueous solution using musa paradisiaca stalk," Ife J of Science, vol. 15, no. 3, pp. 463-476, 2013.

[19] Z. Aksu, A. Çalik, A. Y. Dursun, and Z. Demircan, "Biosorption of iron(III)-cyanide complex anions to Rhizopus arrhizus: application of adsorption isotherms," Process Biochemistry, vol. 34, no. 5, pp. 483-491, 1999.

[20] M. T. Çalik, M. S. Islam, and M. Z. Abedin, "Adsorption of phenol from aqueous solution by water hyacinth ash," $A P N$ Journal of Engineering and Applied Sciences, vol. 2, no. 2, pp. 11-17, 2007.

[21] R. Apiratikul and P. Pavasant, "Batch and column studies of biosorption of heavy metals by Caulerpa lentillifera," Bioresource Technology, vol. 99, no. 8, pp. 2766-2777, 2008.

[22] R. R. Leyva, M. J. R. Rangel, B. J. Mendoza, R. L. Fuentes, and C. R. M. Guerrero, "Adsorption of cadmium (II) from aqueous solution on to activated carbon," Water Science and Technology, vol. 35, no. 7, pp. 205-211, 1997.

[23] A. C. Gonçalves, H. Nacke, D. Schwantes et al., "Adsorption mechanism of chromium(III) using biosorbents of Jatropha curcas L," Environmental Science and Pollution Research, vol. 24, no. 27, pp. 21778-21790, 2017.

[24] A. C. Gonçalves Jr., L. Strey, C. A. Lindino, H. Nacke, D. Schwantes, and E. P. Seidel, "Applicability of the Pinus bark (Pinus elliottii) for the adsorption of toxic heavy metals from aqueous solutions," Acta Scientiarum. Technology, vol. 34, no. 1, 2012.

[25] W. M. Antunes, A. S. Luna, C. A. Henriques, and A. C. A. Costa, "An evaluation of copper biosorption by a brown seaweed under optimized condition," Electronic Journal of Biotechnology, vol. 6, pp. 174-184, 2003.

[26] R. Uebelhack, R. Busch, F. Alt, Z.-M. Beah, and P.-W. Chong, "Effects of cactus fiber on the excretion of dietary fat in healthy subjects: a doble blind, randomized, placebo-controlled, crossover clinical investigation," Current Therapeutic Research, Clinical and Experimental, vol. 76, pp. 39-44, 2014.

[27] L. Wang, Z. Chen, J. Yang, and F. Ma, "Pb (II) biosorption by compound bioflocculant: performance and mechanism," Desalination and Water Treatment, vol. 53, no. 2, pp. 421-429, 2013.

[28] P. Panida, M. Sajeva, M. Bruno, S. Rosselli, and A. Maggio, "Essential oils composition of two Sicilian cultivars of Opuntia ficus-indica (L.) Mill. (Cactaceae) fruits (prickly pear)," Natural Product Research, vol. 27, no. 14, pp. 13051314, 2014.

[29] Y. Bulut and Z. Baysal, "Removal of $\mathrm{Pb}$ (II) from wastewater using wheat bran," Journal of Environmental Management, vol. 78, no. 2, pp. 107-113, 2006.

[30] J. C. Igwe, A. A. Abia, and C. A. Ibeh, "Adsorption kinetics and intraparticulate diffusivities of $\mathrm{Hg}$, as and $\mathrm{Pb}$ ions on unmodified and thiolated coconut fiber," International Journal of Environmental Science \& Technology, vol. 5, no. 1, pp. 83-92, 2007. 
[31] A. O. Dado, A. P. Olalekan, A. M. Olatunya, and O. Dada, "Langmuir, Freundlich, temkin and dubinin-radushkevich isotherms studies of equilibrium sorption of $\mathrm{Zn}^{2+}$ unto phosphoric acid modified rice husk," IOSR Journal of Applied Chemistry, vol. 3, no. 1, pp. 38-45, 2012.

[32] J. Hu, C. Chen, X. Zhu, and X. Wang, "Removal of chromium from aqueous solution by using oxidized multiwalled carbon nanotubes," Journal of Hazardous Materials, vol. 162, no. 2-3, pp. 1542-1550, 2009.

[33] B. Preetha and T. Viruthagiri, "Batch and continuous biosorption of chromium(VI) by Rhizopus arrhizus," Separation and Purification Technology, vol. 57, no. 1, pp. 126-133, 2007.

[34] X.-j. Wang, S.-q. Xia, L. Chen, J.-f. Zhao, J.-m. Chovelon, and J.-r. Nicole, "Biosorption of cadmium(II) and lead(II) ions from aqueous solutions onto dried activated sludge," Journal of Environmental Sciences, vol. 18, no. 5, pp. 840-844, 2006.

[35] G. S. Agarwal, H. K. Bhuptawat, and S. Chaudhari, "Biosorption of aqueous chromium(VI) by Tamarindus indica seeds," Bioresource Technology, vol. 97, no. 7, pp. 949-956, 2006.

[36] Y.-S. Ho and A. E. Ofomaja, "Biosorption thermodynamics of cadmium on coconut copra meal as biosorbent," Biochemical Engineering Journal, vol. 30, no. 2, pp. 117-123, 2006.

[37] S. R. Popuri, A. Jammala, K. V. N. S. Reddy, and K. Abburi, "Biosorption of hexavalent chromium using tamarind (Tamarindus indica) fruit shell-a comparative study," Electronic Journal of Biotechnology, vol. 10, no. 3, pp. 358-367, 2007.

[38] P. Pasavant, R. Apiratikul, V. Sungkhum, P. Suthiparinyanont, S. Wattanachira, and T. F. Marhaba, "Biosorption of $\mathrm{Cu}^{2+}, \mathrm{Cd}^{2+}$, $\mathrm{Pb}^{2+}$, and $\mathrm{Zn}^{2+}$ using dried marine green macroalga Caulerpa lentillifera," Bioresource Technology, vol. 97, no. 18, pp. 2321-2329, 2006. 